\title{
Women neurosurgeons around the world: a systematic review
}

\author{
Tina Lulla, BA, ${ }^{1}$ Rosemary T. Behmer Hansen, MA, MPH, ${ }^{1}$ Cynthia A. Smith, JD, ${ }^{1}$ \\ Nicole A. Silva, MD, ${ }^{2}$ Nitesh V. Patel, MD, ${ }^{1}$ and Anil Nanda, MD, MPH ${ }^{1}$
} 1Department of Neurosurgery, Rutgers New Jersey Medical School, Newark, New Jersey; and 'Department of Neurosurgery,
University of North Carolina, Chapel Hill, North Carolina

OBJECTIVE Gender disparities in neurosurgery have persisted even as the number of female medical students in many countries has risen. An understanding of the current gender distribution of neurosurgeons around the world and the possible factors contributing to country-specific gender disparities is an important step in improving gender equity in the field.

METHODS The authors performed a systematic review of studies pertaining to women in neurosurgery. Papers listed in PubMed in the English language were collected. A modified grounded theory approach was utilized to systematically identify and code factors noted to contribute to gender disparities in neurosurgery. Statistical analysis was performed with IBM SPSS Statistics for Windows.

RESULTS The authors identified 39 studies describing the density of women neurosurgeons in particular regions, 18 of which documented the proportion of practicing female neurosurgeons in a single or in multiple countries. The majority of these studies were published within the last 5 years. Eight factors contributing to gender disparity were identified, including conference representation, the proverbial glass ceiling, lifestyle, mentoring, discrimination, interest, salary, and physical burden.

CONCLUSIONS The topic of women in neurosurgery has received considerable global scholarly attention. The worldwide proportion of female neurosurgeons varies by region and country. Mentorship was the most frequently cited factor contributing to noted gender differences, with lifestyle, the glass ceiling, and discrimination also frequently mentioned. Future studies are necessary to assess the influence of country-specific sociopolitical factors that push and pull individuals of all backgrounds to enter this field.

https://thejns.org/doi/abs/10.3171/2020.12.FOCUS20902

KEYWORDS gender; female; women; systematic review; neurosurgery

A RECENT estimate of the total number of neurosurgeons globally, including trainees, was reported to be $49,940 .{ }^{1}$ The global neurosurgeon workforce density ranges greatly from country to country, with deficits seen most commonly in low- and middle-income countries (LMICs). The literature demonstrates that 33 countries have zero neurosurgeons. ${ }^{1}$ An increase in the neurosurgical workforce is necessary to meet the growing burden of neurosurgical diseases, such as cerebrovascular accidents and traumatic brain injury., 1,2 These neurosurgical diseases contribute significantly to the global incidence of disability. ${ }^{2}$ In anticipation of these increasing needs, global and neurosurgical organizations are collaborating to increase access to neurosurgical care. ${ }^{1}$

Historically, neurosurgery has been a male-dominated field, with gender disparities still persisting today. Many medical fields have made strides toward gender equity, yet surgical fields continue to have higher percentages of men than women. ${ }^{3}$ While $50.7 \%$ of students entering medical school in the United States in 2017 were women, the physician specialty report produced by the Association of American Medical Colleges (AAMC) in 2017 showed that only $8.4 \%$ of neurosurgeons in the United States are women. ${ }^{3,4}$ In 2008, the American Association of Neurological Surgeons (AANS) asked the leadership of Women in Neurosurgery (WINS) to publish a white paper on the recruitment and retention of female neurosurgical residents and practitioners. ${ }^{5}$ The paper demonstrated that there are consistently low numbers of women in neurosurgery training programs and cited a lack of female role models for mentoring of residents and junior faculty, among other causative factors. ${ }^{5}$ 
This systematic literature review aims to be the first to describe the current gender distribution of neurosurgeons across the world. In addition, we review and evaluate factors hypothesized by the authors of these studies to contribute to country-specific or culture-dependent gender disparities.

\section{Methods}

We conducted a study to compile articles describing the density of women neurosurgeons globally. We performed a systematic literature review of peer-reviewed articles using PubMed on September 14, 2020. Search terms included "women AND neurosurgeon," "women AND neurosurgery," "women AND neurological surgery," "gender AND neurosurgeon," "gender AND neurosurgery," "gender AND neurological surgery," "female AND neurosurgeon," "female AND neurosurgery," and "female AND neurological surgery." All studies that displayed any of these terms in the title or abstract were collected for further review.

Our initial search returned 1679 results. Key inclusion criteria were mention of location (country or region) in the title or abstract, study of women in neurosurgery, available in English (written or translated), and reporting on incidence, prevalence, or other data regarding women in neurosurgery. Specifically, studies were included if they mentioned any figure regarding a rate of women in neurosurgical training, residency, fellowship, the workforce, and/or academia. Exclusion criteria included articles published in books and those for which full manuscripts could not be acquired through our institutional library. Our lack of access to papers beyond those available via our institution, in particular, likely led to the exclusion of some foundational works from our review. After applying inclusion and exclusion criteria, 159 preliminary studies were identified. Upon review of abstracts, 87 studies were selected, and ultimately 39 studies were included. Of the 48 excluded studies, many were removed due to lack of data or statistics on gender and neurosurgery on their reported regions. Studies were reviewed by two authors of this analysis to maintain internal validity in categorization, inclusion, and exclusion. The full PRISMA model detailing our systematic review process is shown in Fig. 1. The primary location discussed within each study was coded.

Articles were analyzed to determine factors that contributed to the gender disparity in neurosurgery. A modified grounded theory approach was utilized to systematically identify and code these factors. Two authors participated in the coding process to maintain internal validity. Factor coding and creation of new categories were continued until no new themes were identified. Ultimately, 8 thematic categories were created: 1) conference representation, including participating in, presenting at, and speaking at professional academic conferences; 2) "glass ceiling" in medicine, referring to unequal opportunities for women in the workplace, inhibiting their professional advancement; 3) lifestyle, including work-life balance, personal goals, and family goals/commitments; 4) mentoring, including factors such as professional support, professional mentorship, and networking; 5) discrimination, including overt and covert discouragement from entering the field, the presence of gender roles and expectations within the field, and the presence of both overt and covert gender-based harassment of any kind; 6) interest, referring to interest in the content and practice of neurosurgery, as well as career satisfaction in the performance of neurosurgery; 7) salary, referring to forms of compensation and funding for performance of neurosurgical work; and 8) physical burden, referring to the physical nature of performing neurosurgical procedures and delivering neurosurgical care.

Finally, of the 39 total studies identified for inclusion in this study, we performed an additional subgroup analysis to identify those studies that specifically document the rate of practicing female neurosurgeons in a single or in multiple countries. Ultimately, 18 studies were included in this subset analysis. The data from these 18 studies were compiled to construct a global map of female neurosurgeon density. Importantly, for instances in which multiple studies shared conflicting statistics regarding the prevalence of female neurosurgeons in a country, the statistic collected most recently was utilized in listing the global rate for the said country. Due to the heterogeneity of data collected with country-specific dates, the global map includes only the most recent data available per country. This is an important limitation of our analysis and, as a result, comparisons between countries must be made with caution.

Statistical analysis was completed using IBM SPSS Statistics for Windows (version 23.0, IBM Corp.). Variables for which data were collected included continent of analysis, country or countries of analysis, type of study, year of study, and proportion of female neurosurgeons (if included), with the specific date of that data collection. In addition, the number of factors mentioned per each study was assessed. Descriptive information regarding these variables was collected with IBM SPSS Statistics for Windows. Tables and figures were created with Microsoft Excel for Microsoft 365 (Microsoft Corp.). The world map was also created utilizing Microsoft Excel. This study did not require Institutional Review Board approval, as it did not include research with human subjects.

\section{Results}

Thirty-nine studies were utilized in our analysis and are shown in Table 1. Of those, 29 (74.4\%) contained data on a single country and $10(25.6 \%)$ contained data on multiple countries. The studies were of varied types: 21 (53.8\%) studies were cross-sectional, 10 (25.6\%) were retrospective, and $5(12.8 \%)$ were discussions or letters. The remaining three methods, which were represented by 1 study each, were prospective, white paper/position/policy, and literature review. Since 2004, the number of studies published per year on the topic of women in neurosurgery globally has consistently increased. Similarly, the stated factors impacting the proportion of female neurosurgeons have increased and diversified, as seen in Fig. 2.

All of the factors mentioned by studies as contributing to gender disparities are shown in Table 2. Nine (23.1\%) studies did not list any factors contributing to gender disparities. Twelve (30.8\%) studies listed 2 or fewer factors, 
PRISMA 2009 Flow Diagram

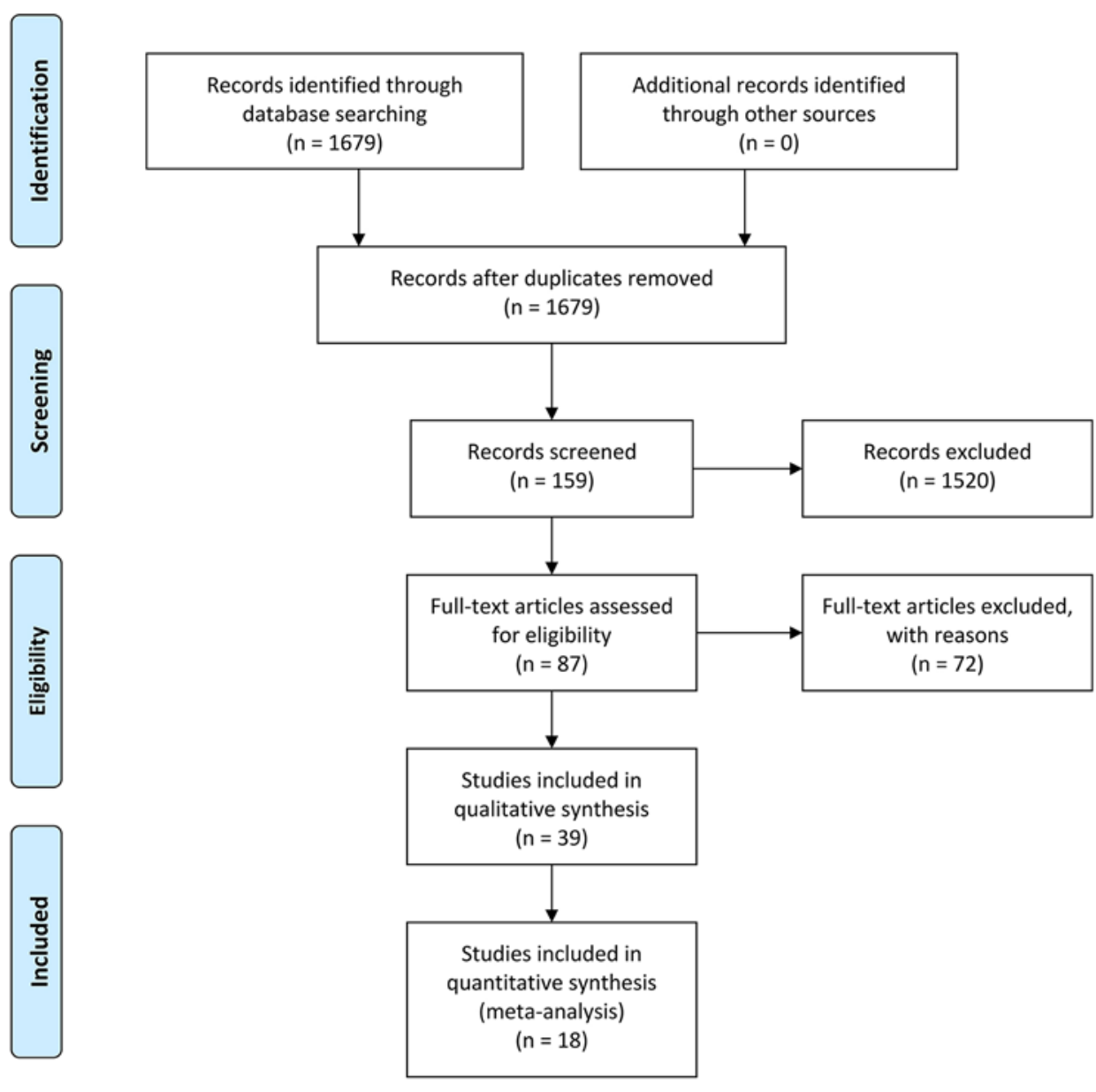

From: Moher D, Liberati A, Tetzlaff J, Altman DG, The PRISMA Group (2009). Preferred Reporting /tems for Systematic Reviews and MetaAnalyses: The PRISMA Statement. PLoS Med 6(7): e1000097. doi:10.1371/journal.pmed1000097

For more information, visit www.prisma-statement.org.

FIG. 1. PRISMA model of study inclusion and exclusion criteria.

while $18(46.2 \%)$ studies list 3 or more factors that contribute to gender disparities in neurosurgery. The most commonly cited factor was mentoring, which was mentioned by $22(56.4 \%)$ studies. The second most common factor was lifestyle (48.7\%), followed by discrimination $(38.5 \%)$ and glass ceiling and unequal opportunities (33.3\%). The least common factors mentioned included conference representation $(15.4 \%)$, salary $(7.7 \%)$, interest in the specialty (4\%), and physical burden (2.6\%). The distribution of factors and percentage of studies citing each factor are shown in Table 3.

Figure 3 shows the number of factors per continent contributing to gender disparities. Mentorship was the most frequently cited factor in North America and Europe. In Asia, mentorship and lifestyle were both cited equally. North America contained the greatest diversity in factors, citing 7 of the 8 factors as contributing to gender dispari- ties, followed by Asia and Europe with 6 and 5 factors, respectively. Asia was the only continent to cite physical burden as a factor $(n=1)$. In studies that provided data on multiple continents, mentorship, lifestyle, glass ceilings, discrimination, and interest were all described as factors.

A majority of studies $(n=29 ; 74.4 \%)$ provided data on a single country, and $25.6 \%$ of studies provided data on multiple countries. The most studied continent overall was North America (48.7\%), followed by Europe (20.5\%) and Asia (17.9\%). In contrast, there were zero studies from Africa and $2(5.1 \%)$ from South America. Three (7.7\%) studies reported data from multiple continents. The distribution of continents represented by the studies is shown in Table 4.

Figure 4 is a global map showing the estimated percentage of female neurosurgeons around the world by country. Overall, Italy reported the highest proportion of female neurosurgeons at $36 \%$, followed by El Salvador (29.3\%) 
TABLE 1. Final studies included in the systematic literature review

\begin{tabular}{|c|c|c|c|c|}
\hline Authors \& Year & Study Type & Countries Discussed & Rate Type & $\begin{array}{l}\text { Included in Global } \\
\text { Map Creation }\end{array}$ \\
\hline Kato et al., $2004^{29}$ & Cross-sectional & Japan & National & Yes \\
\hline Woodrow et al., $2006^{44}$ & Literature review & Canada, USA & National, neurosurgery residents & Yes \\
\hline $\begin{array}{l}\text { WINS White Paper } \\
\text { Committee et al., } 2008^{5}\end{array}$ & $\begin{array}{l}\text { White paper/posi- } \\
\text { tion/policy paper }\end{array}$ & USA & $\begin{array}{c}\text { National, academic } \\
\text { neurosurgeons }\end{array}$ & Yes \\
\hline Day et al., $2010^{23}$ & Cross-sectional & USA & Neurosurgery workforce & No \\
\hline Fukuda \& Harada, $2010^{28}$ & Cross-sectional & Japan & Medical students & No \\
\hline Zanon, $2011^{46}$ & Discussion/letter & Brazil & National & Yes \\
\hline Crowley et al., $2012^{21}$ & Cross-sectional & USA & $\begin{array}{l}\text { Neurosurgery resident } \\
\text { publications }\end{array}$ & No \\
\hline Wilkes et al., $2015^{42}$ & Cross-sectional & Great Britain, Ireland & National & Yes \\
\hline Lynch et al., $2015^{34}$ & Retrospective & USA & National, neurosurgery residents & Yes \\
\hline Awad et al., $2016^{19}$ & Retrospective & USA & $\begin{array}{l}\text { Neurosurgery research grants } \\
\text { awarded to medical students }\end{array}$ & No \\
\hline Renfrow et al., $2016^{7}$ & Cross-sectional & USA & $\begin{array}{c}\text { Neurosurgery residents, resident } \\
\text { attrition }\end{array}$ & No \\
\hline Darwazeh et al., $2017^{22}$ & Discussion/letter & Palestine & National & Yes \\
\hline Steklacova et al., $2017^{12}$ & Cross-sectional & $\begin{array}{c}\text { Albania, Austria, Belgium, Bosnia-Herzegovina, } \\
\text { Bulgaria, Croatia, Cyprus, Czech Republic, } \\
\text { Denmark, Estonia, Finland, France, Germany, } \\
\text { Greece, Hungary, Israel, Italy, Kazakhstan, } \\
\text { Kosovo, Latvia, Lithuania, Moldova, Nether- } \\
\text { lands, Poland, Portugal, Romania, Russia, } \\
\text { Serbia, Slovakia, Spain, Sweden, Switzerland, } \\
\text { Turkey, UK, Ukraine }\end{array}$ & National & Yes \\
\hline Epstein, $2017^{26}$ & Retrospective & Great Britain, Ireland & National & Yes \\
\hline Durham et al., $2018^{24}$ & Retrospective & USA & $\begin{array}{c}\text { National, neurosurgery residency } \\
\text { applicants }\end{array}$ & Yes \\
\hline Shakir et al., $2018^{40}$ & Cross-sectional & USA & Neurosurgery resident burnout & No \\
\hline Renfrow et al., $2018^{39}$ & Retrospective & USA & Neurosurgery residents & No \\
\hline Agarwal et al., $2019^{18}$ & Prospective & USA & Neurosurgery resident attrition & No \\
\hline $\begin{array}{l}\text { Ottenhausen et al., } \\
2018^{38}\end{array}$ & Cross-sectional & Germany, Austria, Switzerland & Neurosurgery resident attrition & No \\
\hline Wolfert et al., $2019^{43}$ & Cross-sectional & $\begin{array}{l}\text { Austria, Belgium, Croatia, Czech Republic, Es- } \\
\text { tonia, France, Germany, Greece, Ireland, Italy, } \\
\text { Latvia, Netherlands, Poland, Portugal, Russia, } \\
\text { Serbia, Spain, Sweden, Turkey, UK, Ukraine }\end{array}$ & Neurosurgical society leadership & No \\
\hline Enchev et al., $2019^{25}$ & Cross-sectional & Bulgaria & Neurosurgery workforce & No \\
\hline Silva et al., $2019^{41}$ & Retrospective & USA & $\begin{array}{c}\text { Opportunity spots at national } \\
\text { conferences }\end{array}$ & No \\
\hline Odell et al., $2019^{15}$ & Cross-sectional & Canada, USA & $\begin{array}{l}\text { National, institutional leadership } \\
\text { positions }\end{array}$ & Yes \\
\hline Ngaage et al., $2019^{37}$ & Cross-sectional & USA & Industry funding & No \\
\hline Dixon et al., $2019^{6}$ & Cross-sectional & Brazil, USA & $\begin{array}{c}\text { National (Brazil), medical } \\
\text { students (USA) }\end{array}$ & Yes \\
\hline Nadel et al., $2019^{36}$ & Retrospective & Canada, USA & $\begin{array}{l}\text { Pediatric neurosurgery } \\
\text { residents/surgeons }\end{array}$ & No \\
\hline Kilinc et al., $2019^{30}$ & Cross-sectional & Germany & Neurosurgery residents & No \\
\hline Lauretti, 201932 & Discussion/letter & Italy & Neurosurgery residents & No \\
\hline $\begin{array}{l}\text { Palanisamy \& } \\
\text { Battacharjee, 201910 }\end{array}$ & Cross-sectional & India & National & Yes \\
\hline Jung et al., $2019^{14}$ & Discussion/letter & Korea & National, neurosurgery residents & Yes \\
\hline
\end{tabular}


» CONTINUED FROM PAGE 4

TABLE 1. Final studies included in the systematic literature review

\begin{tabular}{|c|c|c|c|c|}
\hline Authors \& Year & Study Type & Countries Discussed & Rate Type & $\begin{array}{l}\text { Included in Global } \\
\text { Map Creation }\end{array}$ \\
\hline Klifto et al., $2020^{31}$ & Retrospective & USA & Neurosurgery residents & No \\
\hline Yaeger et al., $2020^{45}$ & Retrospective & USA & Neurosurgery residents & No \\
\hline $\begin{array}{l}\text { Behmer Hansen et al., } \\
2020^{20}\end{array}$ & Cross-sectional & USA & Academic neurosurgeons & No \\
\hline $\begin{array}{l}\text { Soriano Sánchez et al., } \\
2020^{13}\end{array}$ & Cross-sectional & $\begin{array}{c}\text { Bolivia, Brazil, Chile, Colombia, Cuba, Domini- } \\
\text { can Republic, Ecuador, El Salvador, Guatemala, } \\
\text { Honduras, Mexico, Panama, Paraguay, Peru, } \\
\text { Portugal, Spain, Uruguay, Venezuela }\end{array}$ & National & Yes \\
\hline Lawson McLean, $2020^{33}$ & Cross-sectional & Germany & $\begin{array}{l}\text { National, institutional leadership, } \\
\text { conferences }\end{array}$ & Yes \\
\hline Maehara et al., $2020^{9}$ & Cross-sectional & Japan & Practicing female neurosurgeons & No \\
\hline $\begin{array}{l}\text { Munakomi \& } \\
\text { Bajracharya, } 2020^{35}\end{array}$ & Discussion/letter & Nepal & National & Yes \\
\hline Gadjradj et al., $2020^{8}$ & Cross-sectional & NA & Practicing neurosurgeons & No \\
\hline Farhan et al., $2020^{27}$ & Retrospective & Worldwide & Practicing neurosurgeons & No \\
\hline
\end{tabular}

$\mathrm{NA}=$ not applicable.

and Germany (29\%). In Europe, after Italy and Germany, Denmark reported 26\% and Finland reported 25\% female neurosurgeons. The smallest proportions of female neurosurgeons were noted in Cyprus and Kosovo, with $0 \%$ each. In Asia, Nepal had the highest reported proportion at $7.1 \%$ and South Korea the lowest at $1.7 \%$. Uruguay reported the highest percentage in South America at 25.8\%, followed by Venezuela at $12.5 \%$. Guatemala and Paraguay had the smallest proportion of female neurosurgeons in South America at $2.5 \%$ and $5.0 \%$, respectively. After El Salvador, Honduras reported the second highest percentage of female neurosurgeons in North America at $10.53 \%$. The United States reported 7.8\% of neurosurgeons as female. Table 5 lists each country, the corresponding proportion of female neurosurgeons, and the year the proportion was determined.

\section{Discussion}

We performed a systematic review of the literature pertaining to women in neurosurgery and identified 39 studies for inclusion. In addition, we used modified grounded theory to create 8 thematic categories to encompass all factors mentioned to be contributors to gender disparities. Our results indicate that the topic of women in neurosurgery has global interest and is being discussed with increasing frequency in countries around the world. The earliest study included in our analysis was published in 2004. Since then, the number of studies published per year focusing on women in neurosurgery has consistently increased, with the majority $(\mathrm{n}=32 ; 82.5 \%)$ published after the year 2015. In addition, we demonstrated that gender disparity in neurosurgery is a complex issue, with $46.2 \%$ of studies describing 3 or more contributing factors. To our

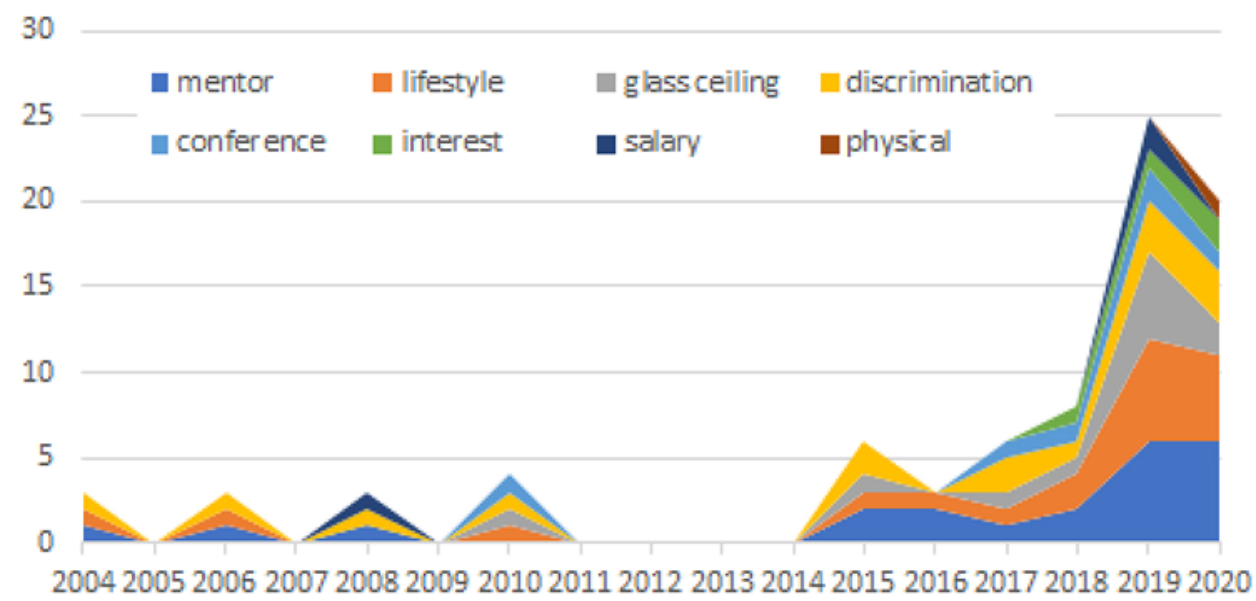

FIG. 2. Number of factors mentioned per year. 
TABLE 2. Number of factors contributing to gender difference by number of studies mentioning said factors

\begin{tabular}{cc}
\hline No. of Factors & No. (\%) of Studies \\
\hline 0 & $9(23.1)$ \\
\hline 1 & $7(17.9)$ \\
\hline 2 & $5(12.8)$ \\
\hline 3 & $9(23.1)$ \\
\hline 4 & $8(20.5)$ \\
\hline 5 & $1(2.6)$ \\
\hline
\end{tabular}

knowledge, this is the first systematic review of its kind to assess the published literature on the global distribution of women in neurosurgery and the factors contributing to the current trends in this important area. Importantly, this review could not capture all studies pertaining to this topic or all global regions, and further analyses by diverse authors from diverse countries will inevitably generate additional critical data.

Overall, 55 (28.2\%) countries were represented in the 39 studies included in our review. North America was the most studied continent, with the majority of the data focused on the United States. Europe and Asia were also highly represented, with 8 and 7 studies each, respectively. However, no study in our analysis included data with rates for Australia and Africa. We find it critical to acknowledge that our study reports on the proportions of reported female neurosurgeons in each country; it does not document the absolute numbers of neurosurgeons of any gender per country. For more information on the global neurosurgical workforce, we encourage readers to access the excellent World Federation of Neurosurgical Societies global workforce map at https://www.wfns.org/menu/61/global-neurosurgical-workforce-map.

\section{Contributing Factors}

Mentorship was the most frequently cited factor in the studies identified by this analysis, with $22(56.4 \%)$ studies mentioning it as impactful. Mentorship has also been consistently listed as a factor throughout the time period studied, beginning with the earliest study included in our analysis, published in 2004, and this factor has been discussed in studies across multiple continents. Mentoring plays a crucial role for all trainees, but it has been found to have a particularly strong impact on women, especially in male-dominated fields. ${ }^{5-7}$ Female medical students are more likely to enter programs with a higher proportion of female residents. ${ }^{6,7}$ Mentorship has also been shown to improve recruitment as well as retention of women into neurosurgery. A survey of female medical students at a single institution in the United States found that female mentor availability was associated with increased likelihood of pursuing neurosurgery. ${ }^{6}$ Similarly, Renfrow et al. examined trends in resident enrollment and attrition in the United States from 2000 to 2009 and found that of the top 10 neurosurgery programs with the greatest number of women matched in the decade, 8 programs had low attrition numbers of women students.?

Lifestyle, including work, family goals, and personal
TABLE 3. Factor distribution among total studies assessed

\begin{tabular}{lc}
\hline \multicolumn{1}{c}{ Factor } & No. (\%) \\
\hline Conference & $6(15.4)$ \\
\hline Glass ceiling & $13(33.3)$ \\
\hline Lifestyle & $19(48.7)$ \\
\hline Mentor & $22(56.4)$ \\
\hline Discrimination & $15(38.5)$ \\
\hline Interest & $4(10.3)$ \\
\hline Salary & $3(7.7)$ \\
\hline Physical & $1(2.6)$ \\
\hline
\end{tabular}

Factor thematic categories: 1) "Conference" representation includes invitations to participate in, present at, and speak at professional academic conferences; 2) "Glass ceiling" in medicine refers to unequal opportunities for women in the workplace, inhibiting their professional advancement; 3) "Lifestyle" includes work-life balance, personal goals, and family goals/commitments; 4) "Mentor"/ mentoring includes factors such as professional support, professional mentorship, and networking; 5) "Discrimination" includes overt and covert discouragement from entering the field, the presence of gender roles and expectations within the field, and the presence of both overt and covert gender-based harassment of any kind; 6) "Interest" refers to interest in the content and practice of neurosurgery, as well as career satisfaction in the performance of neurosurgery; 7) "Salary" refers to forms of compensation and funding for performance of neurosurgical work; and 8) "Physical" burden refers to the physical nature of performing neurosurgical procedures and delivering neurosurgical care.

goals, was the second most cited factor contributing to the current percentage of women in neurosurgery (mentioned in 19 studies, 48.7\%). This factor, too, was mentioned in study reports from all continents, and its consistent presence indicates that these concerns may not be entirely culture specific, and that they may be attributed to the neurosurgical field as a whole. Indeed, lifestyle is a major factor to consider upon entering any career. Gadjradj et al. surveyed 870 members of the Congress of Neurological Surgeons and found that female neurosurgeons rated their career fulfillment as significantly worse than did their male colleagues, despite having similar work hours, days worked per week, and current gross salary. ${ }^{8}$ Female respondents were also less likely to be married and to have children than their male counterparts. ${ }^{8}$ In fact, a survey conducted on women who left their neurosurgical positions in Japan showed that the majority left due to difficulty balancing their neurosurgical career and motherhood (52\%). ${ }^{9}$ Even early in their training, female medical students whose culture or religion emphasized the importance of women in child-rearing were found to be less likely to consider entering neurosurgery, according to a survey from a single institution in the United States. ${ }^{6}$ Furthermore, more residents, both male and female, are leaving surgery than before and are increasingly citing lifestyle considerations as a reason. ${ }^{7}$ In conjunction with our analysis, these data suggest that work-life balance is of increasing importance to incoming surgical trainees regardless of gender. Given that lifestyle is a broad category, further studies are necessary to elucidate the exact factors causing this gender disparity so that targeted interventions can be implemented.

Other consistent factors noted by authors to contribute to existing gender distribution in neurosurgery included 


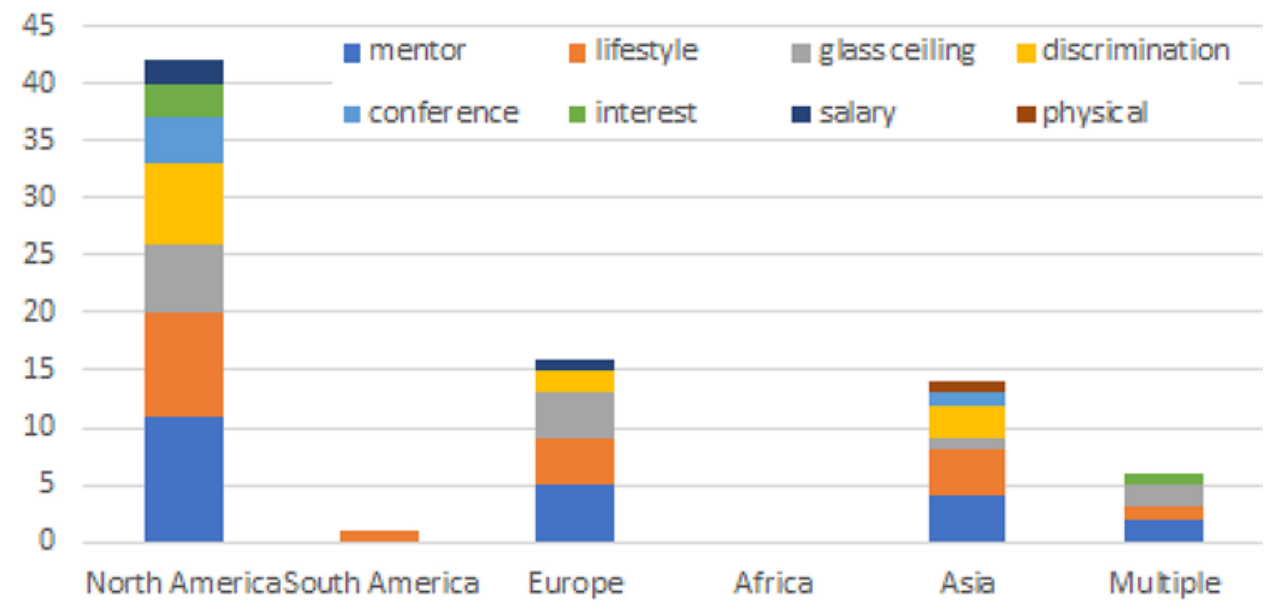

FIG. 3. Number of factors mentioned per continent.

unequal opportunities and discrimination. A survey questionnaire containing 19 questions was designed to assess the barriers faced by Indian women neurosurgeons in 2017; of the 55 who replied, $74.5 \%$ felt they received good support from male colleagues, yet $40 \%$ reported they faced discrimination by gender. ${ }^{10}$ As Bean stated, "The rigor of training or practice does not justify arbitrary barriers to women entering or advancing within the specialty. We cannot afford the failure to attract the brightest and most talented in the applicant pool when they are excluded by subtle and deniable discrimination."'11 It is vital to encourage men in the field to mentor women at every stage of their careers. Having both genders actively involved in nurturing and encouraging women as they progress in their neurosurgical careers can propel women forward professionally. ${ }^{6}$ With increasing awareness and calls for gender equity, we hope that these limiting factors will decrease as we move ahead to equal opportunities, and more women will be seen in academia and in leadership positions.

\section{Global Percentages}

Italy had the highest percentage of female neurosurgeons at 36\%. Other countries with similarly high rates included El Salvador at $29.33 \%$, Denmark at 26\%, Uruguay at $25.81 \%$, and Finland at $25 \%$. These countries all vary significantly in their total numbers of neurosurgeons; Italy reports 1320 total neurosurgeons, while Uruguay reports $31 .^{12,13}$ Many countries also had higher proportions of female neurosurgery residents than board-qualified faculty, indicating that there is a growing enrollment of women in neurosurgery training. ${ }^{12}$ For example, Italy reported that $55 \%$ of their neurosurgical residents were women and Denmark reported $40 \% .^{12}$ These countries also differed in critical variables such as healthcare system infrastructure, median household income, and access to care. Future granular studies assessing the influence of country-specific sociopolitical factors in both pushing and pulling women to enter neurosurgery are desperately needed. Indeed, they are essential to increase the numbers of women neurosurgeons in a variety of locations around the world.

The lowest proportions of female neurosurgeons were reported in the countries of Kosovo (0\%), Cyprus (0\%), South Korea (1.7\%), and Kazakhstan (2\%). Furthermore, $70.8 \%$ of countries were not captured by our review at all, and there remain many countries for which the percentage of female and total neurosurgeons is unknown. Kosovo and Cyprus both reported lower numbers of total neurosurgeons (20 and 22, respectively) and also had few neurosurgery residents (Cyprus reported 2, and resident data were not available from Kosovo). ${ }^{12}$ South Korea reported 3169 total neurosurgeons and Kazakhstan reported 300, on par with countries reporting higher rates of female neurosurgeons. ${ }^{12,14}$ In contrast to many European countries, South Korea also reported a low percentage of female neurosurgery residents: of their 335 residents in 2018, 21 (6.3\%) were women. ${ }^{14}$ The first female South Korean neurosurgeon entered the field in 1983; thus, the timeline of female neurosurgeons in South Korea may not be comparable to the timelines in countries where women entered the field earlier. ${ }^{14}$ Fostering a large network of women neurosurgeons across the globe may help to create a strong network of mentorship and learning opportunities. Efforts to increase the global neurosurgical workforce can be made in conjunction with efforts to achieve gender equity in neurosurgery; expanding mentorship opportunities within the field and mitigating barriers to entering the field may benefit individuals of many backgrounds.

Proportions of female neurosurgeons across continents

TABLE 4. Studies per continent

\begin{tabular}{lc}
\hline Continent & No. (\%) of Studies \\
\hline North America & $19(48.7)$ \\
\hline South America & $2(5.1)$ \\
\hline Europe & $8(20.5)$ \\
\hline Africa & $0(0)$ \\
\hline Asia & $7(17.9)$ \\
\hline Multiple & $3(7.7)$ \\
\hline
\end{tabular}

"Multiple" denotes studies with locations of discussion corresponding to multiple continents. 


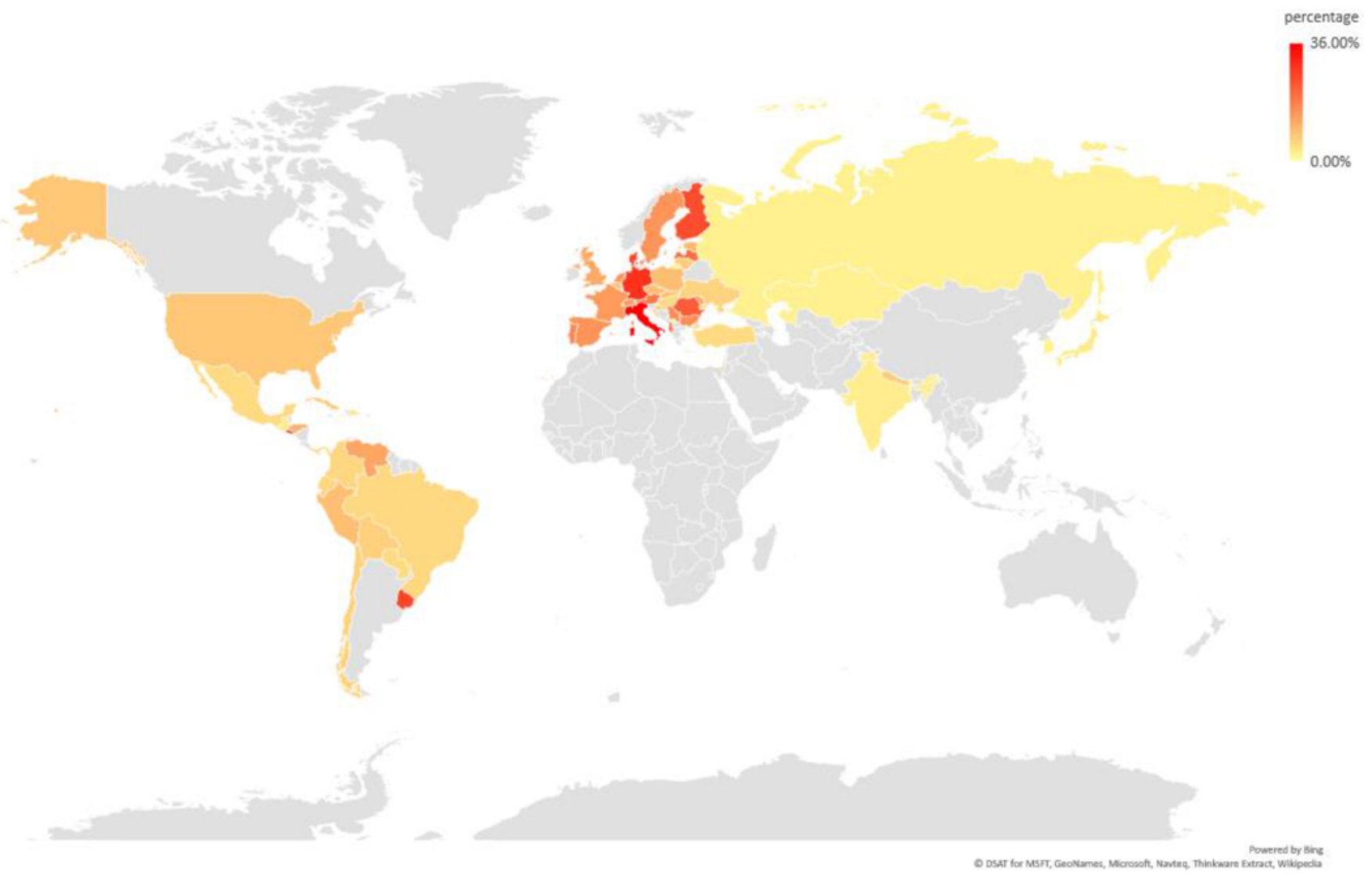

FIG. 4. Miller world map demonstrating the percentages of neurosurgeons who are female, by country. Rates were gathered from subgroup analysis. The map was created with Excel by using data from available studies. Available data were lacking for countries in gray, per our inclusion and exclusion criteria.

can vary dramatically, as seen in the North American, European, and Asian continents. This finding suggests that proportions of female neurosurgeons are not uniform across similar regions. Examination and analysis of cultural and societal norms and practices in countries and regions with both high and low rates of female neurosurgeons may be fruitful to further our understanding of the reasons for gender imbalance in the field. Further scholarship in this area may be helpful in efforts to recruit and retain more women neurosurgeons.

The lack of data available on Africa and Australia is an important limitation of our study, and we would like to caution readers that this finding does not indicate the absence of such studies or of female neurosurgeons in these regions. Indeed, our subgroup analysis ultimately did not capture data from many countries, including Canada. Aggregation of findings in both Canada and the United States indicated that approximately $12 \%$ of neurosurgical faculty of these two nations are women. ${ }^{15}$ While studies by Woodrow et al. ${ }^{44}$ and Odell et al ${ }^{15}$ both discuss Canada and the United States, neither reported a unique rate for Canada individually, ultimately limiting our ability to include a single country-specific proportion for Canada in our final map. We believe this is evidence that our analysis represents the proverbial tip of the iceberg; undoubtedly, future publications with diverse inclusion criteria from varied databases will capture data from countries not currently represented in this article. Anecdotal articles about female neurosurgeons in Africa and Australia are more readily available, along with increasing transparency and networking opportunities through social media. For example, Dr. Ncumisa Jilata received media attention recently for becoming Africa's youngest neurosurgeon. ${ }^{16}$ We hope that our findings excite other women neurosurgeons across the world to share their stories in neurosurgery information outlets, especially as digital connections via virtual conferences and meetings are becoming more common. Increasing international communication and collaboration between female neurosurgeons may foster mentorship as well as encourage more women to enter the field. ${ }^{17}$ Creation of an international database for the compilation of neurosurgeon demographic data would be an ideal means of ensuring that valuable information from all countries is readily available.

Another key limitation of this analysis is the inherent dichotomous use of gender characterization based on the studies included in our review. We trusted each study's methodology to determine gender and used their information as presented. Therefore, this analysis may not show distinctions between surgeon-identified sex and surgeonascribed gender. Our study also does not include other genders, such as nonbinary and transgender. Another limitation is the heterogeneity of data utilized to compose our 
TABLE 5. Proportions of female neurosurgeons displayed in map

\begin{tabular}{|c|c|c|}
\hline Country & Female Neurosurgeons (\%) & Year Determined \\
\hline Albania & 18 & 2016 \\
\hline Austria & 19 & 2016 \\
\hline Belgium & 9 & 2016 \\
\hline Bolivia & 6.67 & $2020^{*}$ \\
\hline Bosnia-Herzegovina & 10 & 2016 \\
\hline Brazil & 5.50 & $2020^{*}$ \\
\hline Bulgaria & 16 & 2016 \\
\hline Chile & 6.27 & $2020^{*}$ \\
\hline Colombia & 5.59 & $2020^{*}$ \\
\hline Croatia & 7 & 2016 \\
\hline Cuba & 8.08 & $2020^{*}$ \\
\hline Cyprus & 0 & 2016 \\
\hline Czech Republic & 9 & 2016 \\
\hline Denmark & 26 & 2016 \\
\hline Dominican Republic & 3.53 & $2020^{*}$ \\
\hline Ecuador & 5.45 & $2020^{*}$ \\
\hline El Salvador & 29.33 & $2020^{*}$ \\
\hline Estonia & 10 & 2016 \\
\hline Finland & 25 & 2016 \\
\hline France & 14 & 2016 \\
\hline Germany & 29 & 2017 \\
\hline Guatemala & 2.50 & $2020^{*}$ \\
\hline Honduras & 10.53 & $2020^{*}$ \\
\hline Hungary & 5 & 2016 \\
\hline India & 2.50 & 2017 \\
\hline Israel & 8 & 2016 \\
\hline Italy & 36 & 2016 \\
\hline Japan & 3.00 & 2004 \\
\hline Kazakhstan & 2 & 2016 \\
\hline Kosovo & 0 & 2016 \\
\hline Latvia & 20 & 2016 \\
\hline Lithuania & 7 & 2016 \\
\hline Mexico & 5.06 & $2020^{*}$ \\
\hline Moldova & 13 & 2016 \\
\hline Nepal & 7.14 & 2017 \\
\hline Netherlands & 15 & 2016 \\
\hline Palestine & 2.90 & 2017 \\
\hline Panama & 5.13 & $2020^{*}$ \\
\hline Paraguay & 5.00 & $2020^{*}$ \\
\hline Peru & 8.87 & $2020^{*}$ \\
\hline Poland & 9 & 2016 \\
\hline Portugal & 17.29 & $2020^{*}$ \\
\hline Romania & 23 & 2016 \\
\hline Serbia & 16 & 2016 \\
\hline Slovakia & 8 & 2016 \\
\hline South Korea & 1.70 & 2018 \\
\hline Spain & 15.00 & $2020^{*}$ \\
\hline Sweden & 15 & 2016 \\
\hline Switzerland & 14 & 2016 \\
\hline
\end{tabular}

CONTINUED IN NEXT COLUMN

\section{» CONTINUED FROM PREVIOUS COLUMN}

TABLE 5. Proportions of female neurosurgeons displayed in map

\begin{tabular}{lcc}
\hline \multicolumn{1}{r}{ Country } & Female Neurosurgeons (\%) & Year Determined \\
\hline Turkey & 5 & 2016 \\
\hline UK & 12 & 2016 \\
\hline Ukraine & 6 & 2016 \\
\hline Uruguay & 25.81 & $2020^{*}$ \\
\hline USA & 7.80 & 2015 \\
\hline Venezuela & 12.50 & $2020^{*}$ \\
\hline
\end{tabular}

Steklacova et al. ${ }^{12}$ provided many of the percentages for Europe, which were reported as whole numbers without decimals.

* Denotes figures gathered from a study published in 2020 (summary of data), for which the specific year of data collection per country was not readily apparent.

global map of female neurosurgeon distribution. As with any systematic literature review, this analysis was inherently limited by the quality of the data collected. Our methodological choices in determining inclusion and exclusion criteria, too, are not immune to criticism. Most critically, our inclusion criterion that studies must be available in English (either written or translated) was fundamentally limiting; many foundational articles were likely not represented.

\section{Conclusions}

Around the world, women perform neurosurgery. We conducted a systematic literature review to compile articles describing the density of women neurosurgeons globally. Our results indicate that the topic of women in neurosurgery has received, and continues to receive, considerable worldwide attention. The issue of gender disparity is complex: 8 thematic categories were necessary to describe all contributing factors mentioned in the literature. Our findings suggest that there is great benefit to fostering global connections for neurosurgeons of all genders. We firmly believe the pursuit of gender equity in neurosurgery need not conflict with broader efforts to increase the global neurosurgical workforce. Future studies are necessary to assess the influence of country-specific sociopolitical factors that both push and pull individuals of all backgrounds to enter this rewarding field.

\section{Acknowledgments}

We thank the Rutgers University Department of Neurosurgery for their support and encouragement in creating this paper.

\section{References}

1. Mukhopadhyay S, Punchak M, Rattani A, et al. The global neurosurgical workforce: a mixed-methods assessment of density and growth. J Neurosurg. 2019;130(4):1142-1148.

2. Dewan MC, Rattani A, Fieggen G, et al. Global neurosurgery: the current capacity and deficit in the provision of essential neurosurgical care. J Neurosurg. 2019;130(4):1055-1064.

3. Association of American Medical Colleges. Active physicians by sex and specialty, 2017. Accessed January 21, 2021. https://www.aamc.org/data-reports/workforce/interactivedata/active-physicians-sex-and-specialty-2017 
4. Association of American Medical Colleges. Women were majority of U.S. medical school applicants in 2018. Published December 3, 2018. Accessed January 21, 2021. https://www. aamc.org/news-insights/press-releases/women-were-majorityus-medical-school-applicants-2018

5. WINS White Paper Committee; Benzil DL, Abosch A, Germano I, et al. The future of neurosurgery: a white paper on the recruitment and retention of women in neurosurgery. $J$ Neurosurg. 2008;109(3):378-386.

6. Dixon A, Silva NA, Sotayo A, Mazzola CA. Female medical student retention in neurosurgery: a multifaceted approach. World Neurosurg. 2019;122:245-251.

7. Renfrow JJ, Rodriguez A, Liu A, et al. Positive trends in neurosurgery enrollment and attrition: analysis of the 20002009 female neurosurgery resident cohort. J Neurosurg. 2016;124(3):834-839.

8. Gadjradj PS, Matawlie RHS, Voigt I, et al. Gender differences between male and female neurosurgeons: is there equality for all? World Neurosurg. 2020;136:348-356.

9. Maehara T, Kamiya K, Fujimaki T, et al. A questionnaire to assess the challenges faced by women who quit working as full-time neurosurgeons. World Neurosurg. 2020;133:331-342.

10. Palanisamy D, Battacharjee $\mathrm{S}$. What it is to be a woman neurosurgeon in India: a survey. Asian J Neurosurg. 2019;14(3): 808-814.

11. Bean J. Women in neurosurgery. J Neurosurg. 2008;109(3):377.

12. Steklacova A, Bradac O, de Lacy P, Benes V. E-WIN Project 2016: evaluating the current gender situation in neurosurgery across Europe-an interactive, multiple-level survey. World Neurosurg. 2017;104:48-60.

13. Soriano Sánchez JA, Perilla Cepeda TA, Birrium Borba LA, et al. Current workforce status of the neurosurgery societies belonging to the Latin American Federation of Neurosurgical Societies: a survey of the presidents of these neurosurgery societies. World Neurosurg. 2020;143:e78-e87.

14. Jung TY, Kim EY, Park MS. Herstory of the Korean Women Neurosurgical Society since 2008. J Korean Neurosurg Soc. 2019;62(6):619-625.

15. Odell T, Toor H, Takayanagi A, et al. Gender disparity in academic neurosurgery. Cureus. 2019;11(5):e4628.

16. Brand South Africa. Dr Ncumisa Jilata: Africa's youngest neurosurgeon. Published June 17, 2017. Accessed January 21, 2021. https://www.brandsouthafrica.com/people-culture/drncumisa-jilata-africas-youngest-neurosurgeon

17. Norton EJ, Bandyopadhyay S, Moudgil-Joshi J. Social media could address the gender gap in neurosurgery. Lancet Neurol. 2020;19(5):382-383.

18. Agarwal N, White MD, Pannullo SC, Chambless LB. Analysis of national trends in neurosurgical resident attrition. $J$ Neurosurg. 2019;131(5):1668-1673.

19. Awad AJ, Sarkiss CA, Kellner CP, et al. Impact of neurosurgery medical student research grants on neurosurgery residency choice. World Neurosurg. 2016;92:349-352.

20. Behmer Hansen RT, Silva NA, Cuevas R, et al. Fellowship, gender, and scholarly productivity: trends among academic neurosurgeons in the US. J Neurosurg. Published online August 28, 2020. doi:10.3171/2020.5.JNS20577

21. Crowley RW, Asthagiri AR, Starke RM, et al. In-training factors predictive of choosing and sustaining a productive academic career path in neurological surgery. Neurosurgery. 2012;70(4):1024-1032.

22. Darwazeh R, Darwazeh M, Sun X. History of neurosurgery in Palestine. World Neurosurg. 2017;104:39-44.

23. Day CS, Lage DE, Ahn CS. Diversity based on race, ethnicity, and sex between academic orthopaedic surgery and other specialties: a comparative study. J Bone Joint Surg Am. 2010; 92(13):2328-2335.

24. Durham SR, Donaldson K, Grady MS, Benzil DL. Analysis of the 1990-2007 neurosurgery residency match: does ap- plicant gender affect neurosurgery match outcome? J Neurosurg. 2018;129(2):282-289.

25. Enchev Y, Brady Z, Arif S, et al. Sexual discrimination in neurosurgery: a questionnaire-based nationwide study amongst women neurosurgeons in Bulgaria. J Neurosurg Sci. Published online November 13, 2019. doi:10.23736/S03905616.19.04814-8

26. Epstein NE. Discrimination against female surgeons is still alive: where are the full professorships and chairs of departments? Surg Neurol Int. 2017;8:93.

27. Farhan SA, Shahid I, Siddiqi J, Khosa F. Assessing the gap in female authorship in neurosurgery literature: a 20-year analysis of sex trends in authorship. World Neurosurg. 2020;141:e661-e669.

28. Fukuda Y, Harada T. Gender differences in specialty preference and mismatch with real needs in Japanese medical students. BMC Med Educ. 2010;10:15.

29. Kato Y, Mihara C, Matsuyama J, et al. Role of women in medicine: a look at the history, the present condition and the future status of women in the surgical field, especially neurosurgery. Minim Invasive Neurosurg. 2004;47(2):65-71.

30. Kilinc F, Gessler F, Dubinski D, et al. Academic output of German neurosurgical residents in 35 academic neurosurgery residency programs. Acta Neurochir (Wien). 2019;161(10): 1969-1974.

31. Klifto KM, Payne RM, Siotos C, et al. Women continue to be underrepresented in surgery: a study of AMA and ACGME data from 2000 to 2016. J Surg Educ. 2020;77(2):362-368.

32. Lauretti L. Tracking career paths of women in neurosurgery. Letter. Neurosurgery. 2019;84(1):E92-E93.

33. Lawson McLean A. Women in German neurosurgery: status and representation at annual national meetings. Acta Neurochir (Wien). 2020;162(2):231-236.

34. Lynch G, Nieto K, Puthenveettil S, et al. Attrition rates in neurosurgery residency: analysis of 1361 consecutive residents matched from 1990 to 1999. J Neurosurg. 2015;122(2):240-249.

35. Munakomi S, Bajracharya A. Reappraising neurosurgical residency in Nepal-stepping stone for paradigm shift from its current perspectives. World Neurosurg. 2020;133:8-9.

36. Nadel JL, Scott RM, Durham SR, Maher CO. Recent trends in North American pediatric neurosurgical fellowship training. J Neurosurg Pediatr. 2019;23(4):517-522.

37. Ngaage LM, Harris C, Gao C, et al. Investigating the gender pay gap in industry contributions to academic neurosurgeons. World Neurosurg. 2019;130:516-522.e1.

38. Ottenhausen M, Anetsberger S, Kleffmann J, et al. Risk factors for dropping out of neurosurgical residency programs-a survey study. World Neurosurg. 2018;120:e100-e106.

39. Renfrow JJ, Rodriguez A, Wilson TA, et al. Tracking career paths of women in neurosurgery. Neurosurgery. 2018;82(4): 576-582.

40. Shakir HJ, McPheeters MJ, Shallwani H, et al. The prevalence of burnout among US neurosurgery residents. Neurosurgery. 2018;83(3):582-590.

41. Silva N, Cerasiello S, Semonche A, et al. Gender representation at neurological surgery conferences. World Neurosurg. 2019; 129:453-459.

42. Wilkes FA, Akram H, Hyam JA, et al. Publication productivity of neurosurgeons in Great Britain and Ireland. J Neurosurg. 2015;122(4):948-954.

43. Wolfert C, Rohde V, Mielke D, Hernández-Durán S. Female neurosurgeons in Europe-on a prevailing glass ceiling. World Neurosurg. 2019;129:460-466.

44. Woodrow SI, Gilmer-Hill H, Rutka JT. The neurosurgical workforce in North America: a critical review of gender issues. Neurosurgery. 2006;59(4):749-758.

45. Yaeger KA, Munich SA, Byrne RW, Germano IM. Trends in United States neurosurgery residency education and training over the last decade (2009-2019). Neurosurg Focus. 2020; 48(3):E6. 
46. Zanon N. Women in neurosurgery: a challenge to change history-Brazil, São Paulo. Childs Nerv Syst. 2011;27(3): 337-340.

\section{Disclosures}

The authors report no conflict of interest concerning the materials or methods used in this study or the findings specified in this paper.

\section{Author Contributions}

Conception and design: all authors. Acquisition of data: Lulla, Silva, Behmer Hansen, Smith. Analysis and interpretation of data: all authors. Drafting the article: Lulla, Smith. Critically revising the article: all authors. Reviewed submitted version of manuscript: all authors. Approved the final version of the manuscript on behalf of all authors: Nanda. Statistical analysis: Behmer Hansen, Smith. Administrative/technical/material support: Lulla. Study supervision: Lulla, Nanda.

\section{Supplemental Information}

Previous Presentations

A version of this paper was presented virtually at the Global Neurosurgery: Ask Not for Whom the Bell Tolls conference on September 11, 2020.

\section{Correspondence}

Anil Nanda: Rutgers New Jersey Medical School, Newark, NJ. ananda.27@rutgers.edu. 